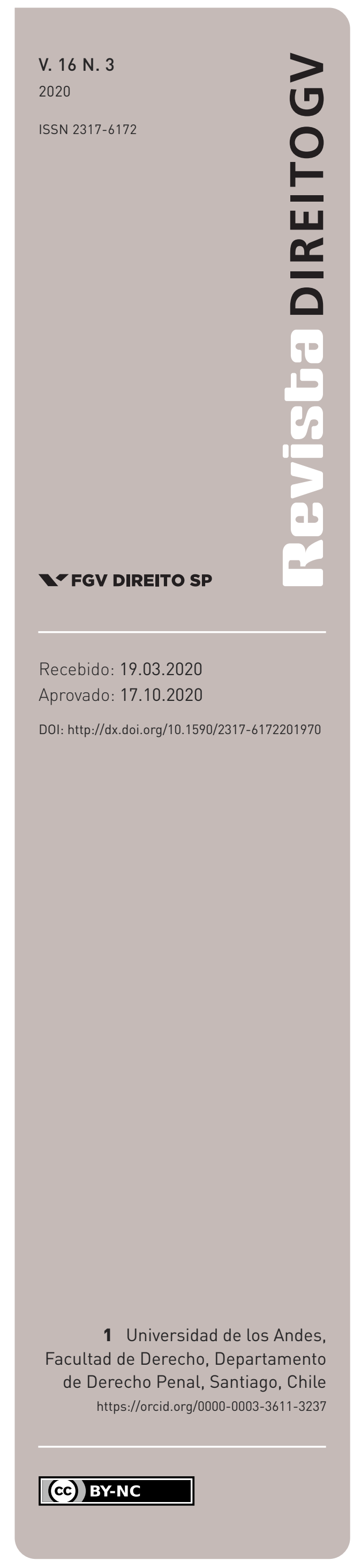

\section{¿Imputación penal por el ámbito de organización de terceros?: el caso chileno de la responsabilidad penal de las personas jurídicas}

CRIMINAL IMPUTATION IN THE ENVIRONMENT OF THE THIRD-PARTY ORGANIZATION?: THE CHILEAN CASE OF CRIMINAL LIABILITY OF LEGAL PERSONS

\author{
IMPUTAÇÃO CRIMINAL NO ÂMBITO DAS PESSOAS COLETIVAS: O CASO CHILENO DA \\ RESPONSABILIDADE PENAL DAS PESSOAS JURIDICAS
}

Gonzalo García Palominos

\section{Resumen}

El artículo tiene por objetivo problematizar el elemento más discutido del sistema de responsabilidad penal de personas jurídicas chileno: la exigencia de que el delito de la persona física sea «consecuencia» del incumplimiento, por parte de la persona jurídica, de los deberes de dirección y supervisión. El artículo propone, como modo de superación de la posible incompatibilidad con el principio de autodeterminación que rige la responsabilidad penal personal, desarrollar criterios de imputación diferenciados y complementarios que permitan sostener la coexistencia de la responsabilidad de la persona física y jurídica. La propuesta final rechaza la analogía «conductual» en la reconstrucción del ilícito de la persona jurídica e invita a orientar la dogmática hacia la generación de «procesos» como manifestación en la realidad social de la «voluntad» de la organización; en este marco, propone el «dominio de la organización sobre el proceso» como principal factor de generación de responsabilidad.

\section{Palabras clave}

Imputación penal; responsabilidad penal de las personas jurídicas; imputación objetiva; responsabilidad vicarial; dominio del proceso.

\begin{abstract}
This paper focuses on the most controversial element of legal persons' criminal liability in Chile: the requirement that the individual's crime must be a "consequence" of the legal person's infringement of management and supervisory duties. In order to overcome the possible incompatibility of such condition with the principle of self-determination that governs personal criminal responsibility, the article proposes to develop differentiated and complementary imputation criteria that allow coexistence of individual and corporate liability. The final proposal rejects the "behavioral" analogy in the reconstruction of the illicit of the legal entity and invites to consider the generation of "processes" as a manifestation of the organization's will in the social reality. Within this framework, it presents "the organization's dominance over the process" as the main factor in causing liability.
\end{abstract}

\section{Keywords}

Criminal imputation; criminal liability of legal persons; objective imputation; vicarious liability; domain of Process.

\section{Resumo}

O objetivo do artigo é problematizar o elemento mais polêmico do sistema de responsabilidade criminal das pessoas coletivas chilenas: a exigência de que o crime 
da pessoa singular seja "consequência" do não cumprimento pela pessoa coletiva dos deveres de direção e supervisão. 0 artigo propõe, como forma de superar a possível incompatibilidade com o princípio da autodeterminação que rege a responsabilidade criminal pessoal, desenvolver critérios de imputação diferentes e complementares que permitam sustentar a coexistência da responsabilidade da pessoa física e jurídica. A proposta final rejeita a analogia "comportamental" na reconstrução do ilícito da pessoa jurídica e convida a orientar a dogmática em direção à geração de "processos" como uma manifestação na realidade social da "vontade" da organização. Nesse contexto, propõe o "domínio da organização sobre o processo" como o principal fator na geração de responsabilidade.

\section{Palavras-chave}

Imputação criminal; responsabilidade criminal de pessoas coletivas; imputação objetiva; responsabilidade vicária; domínio do processo.

\section{INTRODUCCIÓN}

En diciembre de 2009 el ordenamiento jurídico chileno incorporó una nueva modalidad de responsabilidad, a la que le atribuyó naturaleza «penal» y que tiene como sujeto de imputación a las personas jurídicas. Como presupuesto esencial de aquella modalidad se estableció la acreditación de un factor de conexión entre un concreto hecho delictivo, cometido por una persona física y el incumplimiento de deberes de la persona jurídica: «(...) siempre que la comisión del delito fuere consecuencia del incumplimiento, por parte de ésta, de los deberes de dirección y supervisión» (art. 3 de la Ley N²0.393 de 2009). La principal duda radica en que no se trataría solo de una modalidad de responsabilidad penal que acepta modificar el «sujeto de imputación penal» (JAKOBS, 2002, p. 565; VAN WEEZEL, 2010, pp. 114 y ss.; FRISCH, 2013, pp. 813 y ss.) - sin perjuicio de faltar en ella las facultades espirituales de las personas naturales sobre las cuales se ha construido el derecho penal modernosino adicionalmente de una que entiende «compatible» la exigencia de una especie de «relación consecuencial» - que explica la imputación a la persona jurídica por la conducta de la persona física - con la responsabilidad autónoma de la persona física basada en el principio de autodeterminación que rige la responsabilidad personal.

El concepto «consecuencia» desde el punto de vista lingǘstico, en el idioma español, tiene el significado de que un «hecho o acontecimiento se sigue o resulta de otro», ${ }^{1}$ por lo que tiene la virtud de distinguir hechos o circunstancias que son efectos (denominados consecuencias o resultados) de otros hechos o circunstancias que resultan ser sus causas. Por cierto,

\footnotetext{
$\cdots$

1 Véase Diccionario de la Real Academia de la Lengua Española, https://dle.rae.es/?id=AO8fvNk.
} 
la utilización de aquel lenguaje por el legislador da cuenta de una elección de criterios que forman un sistema de responsabilidad «adscriptiva» que considera la causalidad como criterio determinante. La interrogante es si aquel criterio, como sucede en otros órdenes, acude simplemente a vínculos materiales, esto es, a una relación (propiedad) natural y externa entre una circunstancia y otra de la que depende la responsabilidad jurídica (ex post); de una mera relación probabilística (ex ante); o de un vínculo de ilicitud (normativo) entre una circunstancia y un acontecimiento (ex post).

A primera vista, la incorporación de este factor de conexión en el contexto propuesto por la ley podría generar problemas dogmático-penales. Aquello atendiendo a que el concepto «consecuencia» hace referencia a una hipótesis en que un «agente» obra de forma extrínseca sobre otro «agente», produciendo en él un cambio o efecto significativo jurídico penalmente. Desde la perspectiva de la imputación a la persona física, surge el problema de aceptar que su delito podría no ser «consecuencia» autónoma de su autodeterminación individual como sujeto libre, sino que podría estar predeterminado «relevantemente» por la esfera de organización externa de otro agente — que es de carácter fáctica y/o normativa-, por lo que se podría poner en duda su «dominio sobre el hecho» (versión cuantitativa) o, al menos, su vulneración libre e intencionada de la norma de conducta (versión cualitativa). Mientras que, por la perspectiva de la responsabilidad penal de personas jurídicas, surge el problema de aceptar que recaigan cargas y consecuencias «comunicativas» de la pena en ella, sin perjuicio que el delito haya sido previamente imputado individualmente a un tercero (agente) como su propia obra fáctica y normativa.

Adicionalmente, el legislador chileno ha limitado la responsabilidad de los entes solo a las hipótesis en que el delito hubiese sido cometido por sujetos que se encuentran en la cúspide de la organización o sus dependientes directos, lo que genera en muchos de los casos un tercer problema: la responsabilidad de la persona jurídica podría surgir precisamente de la conducta «dolosa» y autorresponsable del órgano encargado de cumplir los deberes en nombre de la persona jurídica (VAN WEEZEL, 2010, p. 135). ${ }^{2}$

Este artículo pretende hacerse cargo precisamente del problema de argumentar dogmáticamente los presupuestos necesarios para poder imputar penalmente responsabilidad a la persona jurídica por el delito atribuido previamente a la autodeterminación de una persona física. Este análisis no se desarrollará desde una lógica de política pública (política criminal), sino esencialmente a partir de consideraciones de lege lata y utilizando el método dogmático. Para tal efecto, el texto se dividirá en cuatro secciones: en la primera de ellas (1.) se pondrá

2 En Chile Van Weezel denuncia que a la persona jurídica se la «castigará penalmente» por la infracción de un deber de cuidado cuyo objeto es (¿impedir?, ¿desincentivar?) la conducta autorresponsable y dolosa de otra persona, misma persona que debía cumplir ese deber de cuidado en el nombre de la persona jurídica. 
en discusión la diferencia entre el concepto jurídico de (atribución de) «responsabilidad»y de «imputación» del derecho penal. Allí se pondrá en relieve el problema jurídico y cultural que genera el reconocimiento de estructuras diseñadas para la responsabilidad civil vicarial y que han sido traspasadas al derecho penal. En la segunda sección (2.) se analizará una vía de solución al problema planteado, sobre la base del reconocimiento de dos dimensiones de la anti-normatividad y de la expresión social, tanto en la conducta humana (persona) como de la organizativa (ente), con capacidad de participar en la producción común de sentido. En la tercera sección (3.) se analizará la coherencia de la perspectiva de solución planteada con las condiciones y presupuestos de la punibilidad en la ley chilena. Finalmente, en la sección cuarta (4.), se desarrolla una propuesta de solución final para la «imputación penal» diferenciada para la persona jurídica y la persona natural.

\section{ASPECTOS GENERALES DEL CONCEPTO DE «IMPUTACIÓN» Y LAS PERSONAS JURÍDICAS: EL PROBLEMA DE FUNDAMENTACIÓN ORIGINAL EN EL DERECHO PENAL}

(I.I) Un primer avance en la aclaración de la problemática parte del reconocimiento de que «atribuir responsabilidad» no es equivalente a imputar (Zurechnung), aunque imputar constituye el principal modo de materializar algunas modalidades de responsabilidad caracterizadas por la atribución de sentido significativo y que considera un proceso de «rendir cuenta personal por una acción» (FLETCHER, 2008, pp. 372 y ss.). Esto porque aun cuando el sistema de responsabilidad de personas jurídicas no es un sistema ético-social completo - al punto de que solo se pretende imponer ciertos efectos comunicativos de la pena a la organización - , se construye a partir de una atribución de sentido que define el merecimiento de pena (KANT, 1979, § 227, p. 35).

La cultura jurídica occidental se afirma, en parte importante, en consideraciones morales y filosóficas. En un sentido algo procedimental, Kant señala que la imputación en su sentido moral (imputatio) es un juicio por medio del cual alguien es considerado autor (Urheber) o artífice (causa libera) de una acción (causa moral), la cual pasa a llamarse acto (factum) y está sometida a leyes (KANT, 1979, §227, p. 35; un rescate y utilización en la dogmática penal HRUSCHKA, 2009, p. 5). Sin embargo, la idea de causa libera da cuenta de un aspecto de fondo: la imputación es atribución a un sujeto «normativo» de un acontecimiento que se califica y juzga como su propia obra libre o causa primaria, desvinculada de otros cursos causales. De hecho, a diferencia del sentido amplio de imputación periférica en Kelsen — como vínculo o juicio de atribución entre un presupuesto o condición normativa y una sanción-, aquí se le quiere destacar como un vínculo entre el injusto y un sujeto, como presupuesto para un efecto; es decir, como imputación central (KELSEN, 1960, pp. 17 y ss.; pp. 27 y s.; pp. 125 y ss.). Aquello es relevante, en tanto la responsabilidad por el comportamiento de un tercero se resuelve de manera diferente según se trate de una mera atribución de 
responsabilidad para la imposición de una carga — reparatoria o disuasoria - o se trate de la imposición de una sanción por atribución de un injusto personal, como en la responsabilidad penal. Esto porque la primera hace referencia al proceso de definición de quien soportara una carga - y que puede comprender a un tercero que no ha configurado un ilícito con su conducta_ _ (en la dogmática chilena más moderna FIGUEROA, 2019, p. 392); mientras que la segunda implicará determinar la pertenencia de una conducta y sus consecuencias «significativas» a un sujeto determinado capaz de manifestar con ella una deslealtad al derecho.

La responsabilidad, en cambio, resulta ser más amplia y se construye sobre contornos más robustos al comprender solo la idea de «cargar por», independiente de la atribución personal fáctica o normativa por una acción libre. Así, por ejemplo, en la responsabilidad extracontractual se utiliza el concepto «responsabilidad» para determinar qué patrimonio soportará el peso económico del daño causado o sufrido por una víctima inocente (carácter reparatorio), sin una mirada prospectiva disuasoria (propia del derecho regulatorio o sancionatorio) y sin una necesaria mirada retrospectiva (como en el derecho penal). De hecho, es capaz de hacerla depender tanto de procesos de atribución fáctica y normativa como en la responsabilidad por culpa, así como por razones sociales o económicas (justicia distributiva), de procesos objetivos sin imputación personal como en la responsabilidad subsidiaria, solidaria y en la vicarial (CELAYA, 1995, pp. 101 y ss.) de carácter objetiva. En este último caso, sin embargo, la atribución no es a un suceso o hecho de un sujeto (por hacer), sino por ser o estar en mejores condiciones de soportar dicha carga. La diferencia es sustantiva.

Al parecer, el origen estaría en el modelo de responsabilidad en las acciones noxales del «derecho penal privado romano» y que tuvieron aplicación en los casos de causación ilícita de daños provocados (por Ley Aquilia o «Edicto del pretor») por animales o por personas incapaces (alieni iuris) y que estaban sujetas a la potestad del paterfamilias o del dominus o, incluso, por el daño causado por los animales (ROSSO, 2016, p. 29). En el derecho romano regía, en principio, la idea de que las personas respondían por los daños que los sujetos causaban individualmente a terceros por su propia iniuria. La «noxalidad», sin embargo, fue una institución del derecho romano que permitía demandar al paterfamilias o al dominus por los daños provocados por alieni iuris o animales, en cuyo caso — y alternativamente- el primero podía pagar la condena (litis aestimatio) o evitar pagar la sanción derivada del ilícito por medio de la entrega del mismo cuerpo que cometió el delito o causó el daño (filius, esclavo o animal) a la víctima para su castigo o resarcimiento; se trata, por lo mismo, de un modelo de responsabilidad que hace recaer los efectos de la sanción en la persona o animal que lo ejecutó. El hecho de que la acción se podía intentar sobre el dueño del esclavo o animal, incluso distinto a aquel que tenía el dominio al momento del hecho, da cuenta de no tratarse de una responsabilidad personal, sino de un traspaso «de los efectos del delito» (o efectos de la sanción) al paterfamilias o dominus por el solo hecho de serlo, de manera de garantizar el interés de la víctima (ROSSO, 2016, pp. 35 y ss.). Aun cuando, con posterioridad, 
la responsabilidad por el hecho del tercero reconoció ciertas circunstancias que limitaban la acción noxal, como en algunas hipótesis de actiones in factum adversus nautas caupones et stabularios, lo importante es que se asentaron dos modos de imputación derivada: la actio furti (objetivo) y actio damni (culpa in eligendo) (ROSSO, 2016, p. 225).

No cabe duda de que aquellos criterios generales del derecho romano fueron traspasados al derecho civil moderno, aceptándose criterios de imputación para la responsabilidad civil extracontractual diseñados a partir de la atribución de «ser o estar en mejores condiciones de reparar» (por justicia distributiva) y/o por atribución al ámbito de la acción (a un proceso, o actividad como hecho). En el derecho civil chileno moderno, al igual que el sistema alemán y a diferencia del derecho francés (modelo francés del art. $1384 \mathrm{CC}$ ), se recoge la responsabilidad civil extraordinaria solo si es consecuencia de la incorporación de normas especiales diseñadas para circunstancias excepcionales (CELAYA, 1995, p. 106), como, por ejemplo, tanto normas introducidas en el Código Civil, como el art. $2320^{3}$ o el art. 2322, ${ }^{4}$ como reglas introducidas en normas especiales, como el art. 886 del Código de Comercio. ${ }^{5}$ La regla general es la exigencia de culpa.

(I.2) En cambio, la responsabilidad penal, en términos generales y a diferencia de la civil, es consecuencia de procesos de imputación personal que buscan determinar la pertenencia de una conducta y sus consecuencias «significativas» a un sujeto determinado con capacidad de producir dicho cambio en el mundo y de manifestar con ella una deslealtad al derecho reprochable ético socialmente. Esto significa que el derecho penal desarrolla —en su parte general — no solamente categorías dogmáticas tendientes a analizar la «conducta típica» injusta (contrariedad a la norma), sino adicionalmente criterios de «imputación»

3 Art. $2320 \mathrm{CC}$ «Toda persona es responsable no sólo de sus propias acciones, sino del hecho de aquellos que estuvieren a su cuidado (...).

Así el padre, y a falta de éste la madre, es responsable del hecho de los hijos menores que habiten en la misma casa.

Así el tutor o curador es responsable de la conducta del pupilo que vive bajo su dependencia y cuidado. Así los jefes de colegios y escuelas responden del hecho de los discípulos, mientras están bajo su cuidado; y los artesanos y empresarios del hecho de sus aprendices o dependientes, en el mismo caso.

Pero cesará la obligación de esas personas si con la autoridad y el cuidado que su respectiva calidad les confiere y prescribe, no hubieren podido impedir el hecho.»

4 Art. $2322 \mathrm{CC}$ «Los amos responderán de la conducta de sus criados o sirvientes, en el ejercicio de sus respectivas funciones; y esto aunque el hecho de que se trate no se haya ejecutado a su vista.»

5 Art. 886. Código de Comercio «El armador responde en la forma que prescriben este Libro y la Ley de Navegación, de las obligaciones contraídas por el capitán que conciernen a la nave y a la expedición. Responde, asimismo, en igual forma, por las indemnizaciones en favor de terceros por los hechos del capitán, oficiales y tripulación.» 
(incriminación) tendientes a definir si al interviniente (autor o partícipe) en el hecho se le puede atribuir el haber tenido la posibilidad de seguimiento de la norma de conducta, de manera tal que su incumplimiento pueda ser definido como una «deslealtad» al derecho. Lo anterior explica que, en el derecho penal, los criterios de imputación se basan en el principio de autorresponsabilidad, de manera tal que la conducta punible es consecuencia de un proceso de «incriminación», esto es, de atribución de responsabilidad por la intervención de un sujeto en la realización del injusto típico. Esto trae como consecuencia que dicho proceso de incriminación se dirija contra todos los intervinientes principales y accesorios por infringir la norma de conducta, en calidad de autores o partícipes en el delito. Responden «diferenciadamente» porque a los autores se les atribuye un injusto más intenso que a los partícipes. Solo excepcionalmente, se puede plantear, como una expresión de deslealtad al derecho, una imputación a un sujeto por la conducta típica ejecutada por un tercero (ejemplo, la autoría mediata o en la complicidad), aunque en todos esos casos se trata de una expresión del injusto penal.

Precisamente, el problema que se plantea en este trabajo surge del reconocimiento de que aquellas estructuras generales de la responsabilidad vicarial (en el derecho penal romano) luego de ser traspasadas al derecho civil (sin imputación personal) han querido ser también traspasadas, sin más, al derecho penal anglosajón (LAUFER, 1999, p. 1362) y, con ello, al sistema de imputación de las personas jurídicas chileno. Aquello, en efecto, acentúa un problema: las principales manifestaciones doctrinarias en el derecho penal anglosajón, según lo ha demostrado la literatura, en el sistema vicarial estricto o en la teoría de la identificación (NIETO MARTÍN, 2008, p. 8), han basado la fundamentación en la lógica civil de justicia distributiva y, en cierta medida, en una lógica de disuasión por cargas. Probablemente, los modelos de heterorresponsabilidad en la «teoría de la identificación» o del «alter ego», al abandonar la idea de mera transferencia de responsabilidad (basada en la justicia distributiva de «control/beneficio») construyeron la base de la responsabilidad moderna de la empresa. Esta se encontraba vinculada con la responsabilidad del empleado/órgano, en la medida que considera la posición del órgano (empleado) en la organización, sea por «identificación» con la empresa (SILVA SÁNCHEZ, 2008, p. 132) o una representación de la voluntad de esta (NIETO MARTÍN, 2008, p. 8; HIRSCH, 1993, pp. 1099 y ss.; en la literatura chilena ORTUZAR, 2012, p. 217). Su expresión, en principio, matizada en el Model Penal Code de 1962 (al respecto véase ROBINSON; DUBBER, 2007, p. 320), al menos en su fundamentación original, no modificó o solucionó en la esencia el problema, ya que solo incorporó elementos de corrección de la atribución dirigidos a la misma organización, excluyendo la responsabilidad en aquellos casos en que se acredite que la persona encargada de supervisar la actividad, dentro de la organización (high managerial agent), en cuyo desarrollo se cometió el delito, «ejerció la diligencia debida para impedir su comisión» (VILLEGAS, 2016, p. 206; UNDANGARIN, 2014). Sin embargo, la lógica de la «mera transferencia de responsabilidad» más bien agudiza la problemática planteada de «imputar» una transgresión normativa de 
sentido transcendente a nivel social, a un sujeto autónomo respecto de la conducta que ya le pertenece a otro, que autorresponsablemente ha sido el «señor» del hecho delictivo.

Por lo mismo, la posibilidad de acceder a estatutos de responsabilidad sin imputación personal (o por el comportamiento ilícito de un tercero), como en la responsabilidad civil subsidiaria, solidaria y en la vicarial (véase, por ejemplo, en las acciones noxales del derecho penal privado romano) (ROSSO, 2016, p. 29), aun cuando estén fundadas en razones de justicia distributiva, deben ser rechazados —al menos por su fundamentación precaria para estos efectos — como modelo de responsabilidad penal.

Así, la cuestión es buscar un tipo de fundamento que, considerando la trascendencia social de la imputación penal — aun cuando estemos frente a personas jurídicas — pueda resolver el problema de significado y de autodeterminación de cada sujeto de imputación (de manera autónoma).

\section{LA DOBLE NATURALEZA DE LOS SUJETOS DE IMPUTACIÓN PENAL: UN PRINCIPIO DE SOLUCIÓN}

(2.I) Más allá de la discusión dogmática — y hasta filosófica — respecto de si las personas jurídicas pueden o no ser sujetos capaces de ejecutar de manera clásica «ilícitos penales» susceptibles de reproche por culpabilidad, (JAKOBS, 2002; GÓMEZ-JARA, 2005, pp. 163182) lo claro es que el legislador chileno sí lo ha considerado posible y «exigible» en alguna forma y grado que, a pesar de algunos desarrollos doctrinarios recientes, no está del todo evidente (art. 3 de la Ley No 20.393 de 2009). Aquella opción, que se ha desarrollado de la mano de una creciente aceptación a la teoría de sistemas, atribuye a las organizaciones una importante relevancia social, lo que le permite implementar un criterio de responsabilidad excepcional. Este criterio reconoce tanto a la persona física como a la jurídica la capacidad de ser sujetos de responsabilidad penal, aunque de manera diferenciada; esto ya que, en principio, serían complementarias (coexisten la responsabilidad de la persona física y jurídica) y, al mismo tiempo, exige que una sea «consecuencia» de la otra . ¿Cómo es aquello posible?

Evidentemente, el comienzo de la explicación no lo podremos encontrar en la clásica teoría de la ficción (a partir de la tesis desarrollada por SAVIGNY, 1840, pp. 235 y ss.) y en su negación a aceptar una capacidad de acción y culpabilidad de las personas jurídicas — ya que al carecer de una verdadera voluntad propia se entiende que solo pueden asumir las obligaciones representadas por sus órganos (personas físicas) (RODRÍGUEZ MOURULLO, 1978, p. 227; BEDECARRATZ, 2015, pp. 43 y ss.). Aquella explicación inicial, al apelar a la ficción, pierde de vista que los entes, en tanto modo de organización humana real (según la teoría de sistemas), tienen capacidad de generar efectos en la vida social, de manera independiente de las personas físicas (ARTAZA, 2013a, p. 179). Aquello reconoce dos modos diferenciados de vincularse socialmente, según se trate de personas naturales con capacidad 
moral o personas jurídicas con capacidad de autoorganización. Precisamente, a dichas capacidades de autoorganización, autorregulación y autodeterminación y que generan efectos sociales (lesividad y cuestionamiento de vigencia de normas) (GÓMEZ-JARA, 2018, p. 83) recurren autores, como Gómez-Jara, para sostener la «culpabilidad» de las organizaciones (GÓMEZ-JARA, 2010, p. 469).

Lo que explicaría su capacidad para «expresar ciertos niveles de injusto merecedor de pena», sin perjuicio de reconocer que las organizaciones son incapaces de ejecutar fácticamente los delitos descritos en el Código Penal, sería entonces que su «realidad»e «identidad» - caracterizadas por la interacción múltiple, coordinación, organización y estructura en búsqueda de objetivos comunes - podrían ser fuentes de fenómenos sociales de relevancia penal. Esto en tanto se trata de organizaciones compuestas por seres humanos, en manifestaciones de voluntades y tensiones en torno a estas (agrupación social) configuradas deliberadamente — ya sea como un instrumento de «dominación y control»o de «planeación u organización»- para lograr fines u objetivos específicos, aunque cambiantes (PARSONS, 1966). Dicha organización deliberada generaría, entonces, no solo capacidad de dominación y de organización autónoma, sino que específicamente, como señala Morgan (1996), capacidad de incidir en el entorno, incluyendo las conductas de las personas que interaccionan con ella, a partir de valores, creencias, normas, rituales, políticas y otros «modelos de significados compartidos» (CAMARENA MARTÍNEZ, 2016, p. 146). Así, no solo es posible afirmar un nivel relevante de competencia autónoma de las organizaciones, diferenciada de las personas físicas, sino también de su relación con los elementos del ambiente (CAMARENA MARTÍNEZ, 2016, p. 164) —relación recíproca y no necesariamente neutra - de manera tal de poder influir en su entorno y, al mismo tiempo, ser influenciada positiva y/o negativamente. Así, la perspectiva que es propia a la organización es alternativamente la «funcional» — que destaca la estructura de orden y jerarquización en torno a funciones - y la procesual, esto es, la referida a flujos de procesos. La manifestación fáctica de la voluntad de una organización se verifica, entonces, en la generación de actividades, en flujos de trabajo organizados y coordinados, que resultan estar «alineados», por una parte, con la misión, visión y objetivos estratégicos de la organización y, por otra, de la cultura de esta. Aquello permite a su vez, por medio del control de sus procesos, que instancias superiores de la organización sean capaces de dominarlos y controlarlos por sus «propios medios», por lo que se hace posible considerarlas sujetos de derecho y de «imputación» en un sentido estricto.

(2.2) Sin perjuicio de que el legislador chileno ha accedido a la posibilidad de una especie de responsabilidad penal de las organizaciones [reconociendo un estatuto de persona moral (ARTAZA, 2013a, p. 192) o de ciudadano corporativo (CIGÜELA, 2015, p. 269)], mantiene la lógica de que los fenómenos de la realidad que le interesan, como acciones de relevancia penal, siguen siendo aquellos que tienen su origen en la conducta humana. La definición de delito del art. $1^{\circ}$ del Código Penal sigue siendo entendida como acción humana (voluntaria) 
y, los delitos en particular siguen siendo diseñados para ser ejecutados —en términos amplios de intervención - y atribuidos por y a personas físicas. Aquello obedece a una comprensión de que socialmente el delito es un modo especial de expresión ético-social exclusivamente humana que tiene valorativamente una expresión fáctica y normativa (ROXIN, AT I, § 8, Nm. 44; 58; 59; con algunos matices en Nm. 29).

Esa decisión de la mayoría de los ordenamientos jurídico-penales en la sociedad occidental moderna puede tener un fundamento antropológico. Solo algunos ejemplos de desarrollos filosóficos y jurídicos, con matices: según ya lo proponía Aristóteles en la «Ética Nicomáquea» o Descartes (res cogitans y res extensa), resulta determinante la diferencia entre acciones personales que tienen al hombre como su principio generador y que tienen a las razones como causa de sus acciones (actos de la volición propios o ámbito del espíritu dominados por la libertad) o, por el contrario, a los meros acontecimientos (Dinamis) que generan una especie de determinismo causal (véase en más profundidad VON DER HEYDT, 2017, pp. 133 y ss.). En Tomas de Aquino, varios siglos después y sin modificar dichos aspectos culturales, ya es posible reconocer una posición intermedia (DE AQUINO, 1986, pars 3, q. 5, a. 1, co. 1). Este autor, siguiendo a Aristóteles, distinguía de entre las ciencias aquellas que versaban sobre el orden de la naturaleza (ciencia natural), de las ciencias humanas vinculadas con el propio pensamiento (lógica), las ciencias de nuestro deliberar (filosofía moral) así como de las artes y la técnica, desarrollando una idea embrionaria: no solo las acciones humanas, sino también los procesos de las agrupaciones en torno a acciones humanas generan más que meros sucesos naturales o meros efectos técnicos. En la medida que están dominados por las decisiones libres, no solo los seres humanos sino también grupos (unidades de orden que se caracterizan por la coordinación y su relación de propósito o sentido) - tales como las sociedades, asociaciones o una comunidad política - pueden desarrollar actividades (acciones humanas) y no solo operaciones (véase en profundidad un análisis más moderno en FINNIS, 2019, p. 27 y ss.). La circunstancia de que los entes se encuentren, sin embargo, en una situación intermedia - esto es, que surgen y se desarrollen a partir de manifestaciones de voluntad e intereses de grupos de seres humanos- no cambia el hecho de que son incapaces de manifestarse espiritualmente y «conductualmente» (sino por medio de sus órganos); aunque no se puede negar que son generadores autónomos de «procesos» dominados enteramente por la racionalidad humana colectiva. Una tesis minoritaria, aunque muy interesante en la cultura jurídica germana clásica, es la desarrollada por Otto von Gierke. Este autor, de una manera un tanto más radical y como contraposición a la teoría de la ficción propia de la cultura romana, propone una forma de entender a las corporaciones como una comunidad que supera la individualidad que, como asociación, configura una unidad. En tanto unidad personal, tiene no solo la capacidad de ser titular de derechos y deberes propio de una abstracción, sino esencialmente voluntad (única y no suma de voluntades) y capacidad de acción propia, y no por medio de terceros. Interesante es que, en esta perspectiva, las asociaciones se conciben como una unidad ético espiritual, 
en que persona y ente se unen indisolublemente (GIERKE, 1963, p. 603 y 743 y ss.; para la aplicación de dicha tesis al derecho penal BEDECARRATZ, 2015, pp. 94 y ss.; un análisis en idioma español PENDAS, 1991-1992, pp. 122 y ss.).

Una expresión solo intermedia resulta ser reconocida en la ley chilena; esto es, por una parte, se entiende que los entes son incapaces de intervenir en la actividad delictual misma (ejecutar) y de expresar ético-socialmente deslealtad a la norma (aunque si de infringirla objetivamente), pero por otra parte y en atención a sus niveles de intervención humana colectiva y complejidad organizacional, se entienden ser sujetos en alguna medida destinatarios de normas y merecedores de pena. Aquello pasa por reconocer también que la reacción penal no se produce en la misma dimensión que aquella impuesta a los seres humanos. En realidad, se trata solo de imponer ciertos efectos comunicativos de la pena a los entes.

Por lo mismo, no parece correcto — al menos, no la interpretación que le podamos atribuir al sistema creado por el legislador chileno a partir de nuestra concepción antropológica-que el reconocimiento del fenómeno lo sea en la dimensión de un comportamiento colectivo (sumatorio) defectuoso de las personas físicas (SCHROTH, 1993, p. 152). Tampoco sería correcto entender que la búsqueda de soluciones del legislador nacional está enfocada en dar respuesta a una especie de «déficit de prevención» radicado en las estructuras complejas de las organizaciones modernas y que generan una «irresponsabilidad individual estructurada» (HEINE, 2006, p. 27), lo que explicaría una adopción de un sistema puramente autónomo (solo excepcionalmente, establece una «aparente» responsabilidad autónoma en el art. 5). Más bien, la aproximación del legislador se acerca a un tipo de fenómeno que, si bien alude genéricamente en la ley al concepto de persona jurídica como ficción (acentuando su capacidad para ser titular de derechos y obligaciones), en la práctica se refiere a las organizaciones complejas con capacidad para influir en su entorno y que sobrepasa la individualidad de las personas que la componen. Incluso cuando su merecimiento y necesidad de pena se exprese solo cuando se haya ejecutado un delito por una persona física. Solo respecto de este fenómeno es que es posible acceder al problema social de riesgos (autónomos al de las personas individuales) y que se manifiesta como una capacidad de influencia en el entorno, ya sea por su cultura corporativa en un sistema defectuoso de organización (LAMPE, 1994, pp. 700 y ss.) o, por ejemplo, como defecto organizativo (TIEDEMANN, 1988, pp. 1169-1172), etc.

Es evidente la opción del legislador chileno (art. 3 y 5), entonces, por un sistema de responsabilidad derivada (mixto) que va a vincular dos subsistemas sociales y normativos distintos (de diferentes dimensiones sociales) — considerando que la única manifestación del injusto penal típico será el de la persona física — pero que, como presupuesto, debe reconocer (vincular funcional y fácticamente) y no «confundir» el fenómeno de la acción individual de la persona física con el fenómeno organizacional como «proceso sistémico lesivo» (HEINE, 2006, p. 27). Esto porque para un sistema de heterorresponsabilidad (o derivada) la fundamentación debe reconocer una «no exclusión recíproca» de responsabilidades (por 
cuestión de diseño del legislador) y, por lo tanto, absoluta autonomía de la persona física (GÓMEZ-JARA, 2006, p. 151).

Lo anterior es posible solo si se considera la responsabilidad de la persona jurídica a partir de la interpretación de sus mismas estructuras de riesgos (ARTAZA, 2013a, p. 179) y de sus propios deberes (y normas de sanción) y no a partir de una analogía a la «acción individual del individuo»(ARTAZA, 2013a, p. 187). Esta última — la conducta - es exclusiva de la persona física. Por tanto, lo relevante es reconocer que las organizaciones son capaces, por un lado, de generar «procesos dinámicos» en busca de objetivos y, por el otro, de motivar dichos procesos por el derecho, de gestionarlos: dirigirlos y controlarlos. Es correcta, entonces, la aproximación de parte importante de la literatura (HEINE, 2006, pp. 30 y ss.; DANNECKER, 2001, pp. 101 y ss.) cuando, distinguiendo la naturaleza de la imputación de la persona física, enfoca su mirada en los déficits de la organización o en la falta de conciencia de sus riesgos y, vinculado a estos, con el desarrollo de sus procesos de dichas organizaciones y, específicamente, su capacidad de comprender en estos la conducta de la persona física. En tanto procesos de naturaleza diferenciada, la relevancia penal para esta última deviene en «merecedora de pena» en la medida que pueda serle atribuido como parte de un «proceso» autoorganizado y dirigido por la propia organización (de su competencia autónoma) e imputado a la manifestación de su ejercicio libre de autoorganización.

Aquello, en lo que a nosotros respecta, genera dos dimensiones no solo de la anti-normatividad, sino que adicionalmente de la realidad social (la psíquica o moral y la meramente organizativa). Aunque, como señala Gómez-Jara (2010, p. 464), con potencialidad de participar en la producción común de sentido.

\section{EL CONTENIDO Y ALCANCE DE LOS DEBERES DE DIRECCIÓN Y SUPERVISIÓN: UN} SISTEMA COHERENTE CON LA LÓGICA DE LOS «PROCESOS»

(3. I) En Chile, el Ministerio Público — encargado de la persecución penal_ ha entendido que, con la fórmula de deberes de dirección y vigilancia, se está intentando abarcar un conjunto de amplias obligaciones y deberes relativos a un «prevenir o evitar resultados delictivos». En efecto, en el Oficio FN N $440 / 2010$ ha sostenido que la responsabilidad de la empresa «es consecuencia del incumplimiento o cumplimiento imperfecto de los deberes de dirección y supervisión de la entidad, que se traducen fundamentalmente en su incapacidad para prevenir su utilización para la comisión de delitos». Aquello, sin embargo, puede ser entendido como un criterio extremadamente vago y dañino, en tanto puede estar limitando desproporcionadamente la libertad de las personas jurídicas, al punto de exigírsele no solo una competencia sobre su propia organización, sino que adicionalmente sobre las conductas voluntarias de terceros y, adicionalmente, sobre la evitación de éstas: derecho de policía. 
No obstante lo anterior, creemos que normativamente el modelo de «responsabilidad penal» chileno de los arts. 3 y 5 de la Ley $N^{\circ} 20.393$ no llega tan lejos, en tanto no se basa en una especie de transferencia de funciones de policía, por parte del Estado a la persona jurídica para que, bajo coacción y por razones prácticas (BEDECARRATZ, 2018, p. 210), asuma la prevención y evitación de todos los delitos desarrollados en su seno (RAGUÉS, 2017, p. 93; KUHLEN, 2014, pp. 103 y ss.), de manera tal que esta última responda por infracción propia al «deber social de prevenir (todos o un grupo de) los delitos».

Por el contrario, la opción del legislador fue configurar un sistema «de verdadera responsabilidad penal», aunque i) asumiendo deberes de autorregulación (regulada) referidos al control de los «propios riesgos» (una especie de modelo de incumbencia) y ii) respecto esencialmente de «delitos corporativos», es decir, de los riesgos generados en la búsqueda de rentabilidad durante la operación del negocio (NIETO MARTÍN, 2017, p. 169). Por lo tanto, se trata de un modelo similar al de las «incumbencias» (HRUSCHKA, 1984, pp. 661 702), de manera que resultan ser deberes limitados al control del propio riesgo (que otorga competencia especial) de ser generador de incentivos para conductas delictivas de terceros vinculados con la organización; aquella vulneración adopta relevancia penal recién cuando es posible aceptar un vínculo de ilicitud entre la vulneración de deberes propios y la conducta delictiva de la persona física. La diferencia entre un modelo (transferencia de deberes de policía) y otro (incumbencia) es relevante, ya que mientras el primero impone una competencia formal a la persona jurídica por el solo hecho de materializarse el delito en su esfera de organización o realizarse por un órgano, el segundo modelo define por generar un nivel de riesgo que exigiría un autocontrol adicional interno. ${ }^{6}$

De ahí que la competencia sobre riesgos de las conductas delictivas de «otros» (autorresponsables) tendría sentido solo si estos se encuentran en el ámbito de conductas motivadas, posibilitadas y/o facilitadas por los incentivos desordenados propios de la organización (competitividad y maximización en la búsqueda de beneficios) (NIETO MARTÍN, 2017, p. 169); esto es, si la conducta de la persona física es de aquellas en que la propia organización tenga algún grado de capacidad de incentivo [por ejemplo, por orientación a la rentabilidad/optimización (PIÑA ROCHEFORT, 2012, p. 24) o el ethos de la empresa (ARTAZA, 2013b, pp. 256 y ss.)] y, por lo tanto, respecto de las cuales la organización deba asumir «excepcionalmente» competencia en el control o la vigilancia de las conductas de terceros autorresponsables.

Considerando que el legislador ha establecido dos deberes diferenciados — el deber de dirección y el de supervisión - se pueden definir sus contenidos, asumiendo la terminología de los deberes de garantía a que hace referencia Heine para estos efectos (HEINE, 2006,

6 Véase el Mensaje del Presidente de la República N 018-357 de marzo 2009. 
p. 36), como de dos tipos: i) uno de correcta organización en virtud del cual, en uso de la libertad empresarial, la empresa se puede organizar libremente según su capacidad autoorganizativa, lo que implica aceptar un determinado riesgo empresarial, pero que no puede superar el permitido (GÓMEZ-JARA, 2015, p. 105). Aquí, Gómez-Jara propone el análisis del riesgo en base al estándar de organización según el buen ciudadano medio empresarial, esto es, el estándar de los programas de cumplimiento habituales del sector que opera una organización básica, etc. (GÓMEZ-JARA, 2015, p. 105). En esta misma línea, Silva Sánchez $(2016$, p. 888) señala que en los sectores regulados el estándar vendrá dado por la propia normativa sectorial, por lo que en los demás casos se remite a la autorregulación, atendiendo a los usos del sector de la actividad, «acuerdos marco» de autorregulación, etc. ii) Finalmente, la asunción de una especie de «garante de supervisión». A pesar de que Heine (2006, p. 36) se refiere a empresas con déficit de organización, aquí parece necesario asumir la necesidad de que toda organización, cualquiera sea su naturaleza y nivel organizacional, puede llegar a transformarse en una estructura que pueda incentivar conductas ilícitas de sus trabajadores y órganos. Por lo mismo, surgiría para esta el deber de organizarse adecuadamente de manera tal que los procesos de la persona jurídica —en el marco de su competencia organizativa — no constituyan un catalizador de conductas delictivas de manera de no generar desproporcionadamente o superar los riesgos de comisión de delitos y, en caso de existir un riesgo, surgiría el deber de «controlar» o supervigilarlos (ZUGALDÍA ESPINAR, 2010). Riesgos de este tipo se presentan en las políticas de negocios que implican tolerancia e, incluso, impulso o incentivo de conductas delictivas (ORTUZAR, 2012, p. 238).

(3.2) El anterior modelo se confirma, además, con el hecho de que la falta de implementación de un programa de cumplimiento no es considerada per se por el sistema como una infracción a los deberes de dirección y vigilancia (art. 4) (HERNÁNDEZ, 2010, p. 227; PIÑA ROCHEFORT, 2012, p. 7) y por el hecho de que dichos programas de cumplimiento son entendidos en su lógica sistematizadora (basada en «procesos» de gestión en la empresa).

Respecto de lo primero (i), se entiende que solo podrá considerarse que la falta de implementación de un programa de cumplimiento constituye una modalidad de vulneración del deber de dirección y vigilancia en aquellos casos que, como señala Silva Sánchez (2014a, p. 195; 2014b, p. 258), por las características de la empresa, la sistematización y procedimentalización (que aportan estos programas) parecen necesarias ex ante. En Chile, autores tales como Hernández (2010, p. 216) y Artaza (2013b, p. 568) han asumido posiciones dogmáticas, proponiendo que el modelo general previsto por el art. 4 deba considerarse como parámetro de cumplimiento de los deberes de prevención delictiva: el primero señala que, en todo caso, se aceptan otras estrategias, pero solo en la medida en que sean tan idóneas como el modelo legal. Artaza, por su parte, parece considerar extremadamente vagas las exigencias de los modelos basados en los parámetros del art. 4, por lo que «parece del todo razonable 
remitirse en este ámbito a la propia práctica del sector empresarial, con el objeto de detectar aquello que se exige a las empresas con relación a la gestión de sus propios riesgos» (ARTAZA, 2013b, p. 569).

Si bien nuestra ley se ha limitado a reconocer la existencia de ciertos deberes de dirección y vigilancia, no es menos cierto que no ha establecido deberes positivos de «evitación» absoluta de los delitos que puedan ser desarrollados por sus empleados y directivos. En particular, el deber se refiere solo a organizarse adecuadamente de manera tal que las actividades de la persona jurídica — en el marco de su competencia organizativa — no constituyan un catalizador de conductas delictivas. Aquello sucedería si las políticas de la empresa generaran desproporcionadamente o superaran los riesgos de comisión de delitos, como la generación de políticas de negocios que impliquen tolerancia, impulso de conductas delictivas (ORTUZAR, 2012, p. 238), hasta el incentivo a las mismas.

Respecto de lo segundo (ii), los programas de cumplimiento, entonces, han sido entendidos por la dogmática coherentemente con la configuración real de las empresas relevantes y complejas y, por lo tanto, con la propuesta de desarrollar una dogmática que reconozca las dos naturalezas (diferenciadas) de los sujetos de imputación. Esto es, entender que estos programas constituyen el diseño de procesos que tienen por objeto «servir de reunión o sistematización de todas aquellas medidas o procedimientos adoptados por la empresa tendientes a asegurar o promover un comportamiento leal al derecho» (ARTAZA, 2013b, p. 558) y, por lo mismo, ordenar las estrategias de cumplimiento de los deberes de dirección y vigilancia; lo que hace un programa de cumplimiento eficiente no es solo optar por una forma de cumplimiento normativo, sino por ir más allá e intentar organizar un proceso de «reducción correlativa de la frecuencia con que se llevan a cabo conductas delictivas en el marco del desarrollo de la actividad empresarial» (ARTAZA, 2013b, p. 548). El estándar de disminución del riesgo de conductas delictivas de terceros, sin embargo, no es un deber exigible a la empresa; aquello sería exageradamente desproporcionado; solo lo es el mantenerse dentro del riesgo permitido, de lo contrario se estaría imponiendo a las personas jurídicas deberes con competencias e intensidades que solo pueden ser cumplidas por la policía, esto es, prevenir y perseguir conductas desarrolladas en ámbitos de autonomía ajena y por sujetos con capacidad de voluntad. Un deber de esas características debería ser expreso y concreto.

(3·3) En efecto, la situación relativa a los programas de cumplimiento y su implementación, si se compara con los modelos italianos y españoles (NEIRA, 2016, p. 482), se diferencia en que estos tienen una lógica de sistematización de cumplimiento de ciertos deberes de dirección y vigilancia orientada a toda la organización (cuestión que queda así diseñada en esos sistemas de imputación) y la penalización se orienta también a los subalternos; en cambio de la relación con el art. 3, la vulneración del deber recibe una relevancia sancionadora recién cuando se conecta con los factores de conexión: cuando se vincula solo con las personas cualificadas y en interés o beneficio de la persona jurídica. 
En España la implementación de programas de cumplimiento tampoco está identificada con el riesgo permitido per se, pero si con la posibilidad de la exclusión de responsabilidad. Neira, de la misma forma que se ha señalado acá, recuerda que, en el caso español e italiano, la implementación de un programa generará un efecto distinto según los sujetos involucrados; así, cuando el sujeto se encuentra en una posición «apical» (o en el vértice) será insuficiente la mera implementación de programas de cumplimiento para eximir a un sujeto de la responsabilidad. Será necesario, además, que el organismo encargado de supervisar el programa haya ejercido debidamente sus funciones y que el sujeto haya eludido fraudulentamente las medidas de control. En ambos casos (implementación y control), sin embargo, la necesidad de acreditar esos requisitos dice relación con una situación inversa a la nuestra: esos requisitos deben ser acreditados para aprovecharse de una eximente, en un supuesto configurado desde la mera transferencia. En el caso nuestro, la eximente no es tan intensa, en tanto no está diseñada para derrotar la mera «transferencia de responsabilidad basada en la identidad», sino para demostrar niveles de cumplimiento de los deberes. El centro del injusto propio de la persona jurídica radica en el incumplimiento «culpable» de los deberes expresamente anunciados en el art. 3, aunque carente de un contenido determinado y explícito en la norma penal.

En conclusión, solo podrá considerarse que la falta de implementación de un programa de cumplimiento constituye una modalidad de vulneración del deber de dirección y vigilancia en aquellos casos que, como señala Silva Sánchez, por las características de la empresa, la sistematización y procedimentalización (que aportan estos programas) parecen necesarias ex ante (SILVA SÁNCHEZ, 2014a, p. 195; 2014b, p. 258). Sin embargo, y contrario a lo que señala dicho autor, dichos programas no constituyen per se un deber cuya vigencia se encuentre penalmente reforzada. Como lo ha afirmado antes Piña Rochefort, la entidad podrá disponer de equivalentes funcionales a los modelos de prevención, esto es, mecanismos de dirección y supervigilancia distintos a los sancionados por la ley, pero que cumplan la misma función (PIÑA ROCHEFORT, 2012, p. 7).

(3.4) Una cuestión adicional a discutir dice relación con la «ampliación» de la punibilidad o sancionabilidad a hipótesis culposas, esto es, a la falta de cuidado en la determinación de ámbitos previsiblemente riesgosos de conductas delictivas y de la falta de cuidado en las políticas de evitabilidad del desarrollo de esos ámbitos. La duda radica en que el injusto de la persona jurídica no reúne las mismas características subjetivas que el injusto doloso de la persona natural, exigido en los delitos base del art. 1 de la ley. Si bien es claro que aquello no podría ser exigido a la persona jurídica, a menos que se acepte la transferencia del dolo de la persona física a la jurídica, en la literatura no se han desarrollado equivalentes funcionales. En el ámbito de la dogmática internacional algunos autores han sostenido que la imputación subjetiva general estaría radicada en «el conocimiento organizativo respecto a los riesgos derivados de su actividad» (GÓMEZ-JARA, 2015, p. 106), mientras que otros han 
ido más allá y han exigido, en la medida que sea posible, que la imputación debe incluir «un conocimiento del riesgo relativo al delito cometido por la persona física», ya que la imputación culposa - de no aceptarse la transferencia y la responsabilidad objetiva - no estaría expresamente prevista por la ley (ROBLES PLANAS, 2015, pp. 233 y s.).

Así, utilizando el ejemplo de Artaza, se hace necesario determinar si el injusto de la persona jurídica solo implica la falta de previsibilidad en el riesgo desarrollado en ciertas dinámicas dadas al interior de la empresa, como políticas de obtención de bonos por resultados, presiones que sean causa de los bajos rendimientos, etc. (ARTAZA, 2013b, p. 569), o, por el contrario, exige un grado más alto de involucramiento en la conducta de un tercero, como grados de tolerancia, ignorancia consciente (vista gorda) o incentivo de dichas conductas.

\section{HACIA UNA PROPUESTA DE IMPUTACIÓN $A$ LA «PERSONA JURÍDiCA» DEL DELITO DE «LA PERSONA FÍSICA»: DOMINIO DEL PROCESO}

Hasta ahora se han concluido dos cuestiones relevantes: i) que el sistema de responsabilidad de las personas jurídicas chileno se configura por la vulneración de deberes de autorregulación referidos al control de los «propios riesgos» (una especie de modelo de incumbencia) por parte de las personas jurídicas y referidos esencialmente a «delitos corporativos» generados en la búsqueda de sus objetivos (por ejemplo, rentabilidad) durante la operación del negocio; y ii) que las conductas de la persona física y los procesos de relevancia social generados por la persona jurídica son diferentes, aun cuándo adopten relevancia jurídico penal cuando se vinculan entre sí. De ahí que ahora resulta necesario definir en qué medida la conducta autorresponsable de la persona física forma parte de los «procesos» dominados, dirigidos y controlados por la persona jurídica que, al mismo tiempo, adoptan una relevancia penal autónoma.

Como se ha señalado más arriba — en la problematización_-, el sistema no ha diseñado un modelo de imputación en que el defecto organizativo fuera razón suficiente para la imputación (HERNÁNDEZ, 2012, p. 85), por lo que lo definitorio como sistema de atribución es determinar la vinculación entre el defecto de organización derivado del incumplimiento de deberes de dirección y vigilancia, y el delito de la persona física, como lo exige expresamente el art. 3: «siempre que la comisión del delito fuere consecuencia del incumplimiento».

$\mathrm{Al}$ respecto, quienes siguen la tesis de Tiedemann en nuestro país, relativa a la «culpabilidad» por defecto organizativo, defienden la idea que dicho defecto representaría la culpabilidad de la persona jurídica, en el sentido que la conducta típica debería ser consecuencia derivada de su propia culpabilidad (ORTUZAR, 2012, p. 238). Por su parte, quienes no siguen esa tesis sostienen que no es posible desconocer la existencia de una especie de tipicidad, donde se analiza dicho defecto como una superación del riesgo permitido — y una culpabilidad propiamente tal—, como equivalente funcional del reproche ético social por deslealtad 
al derecho de las personas naturales radicada en un deficiente cultural de cumplimiento (GÓMEZJARA, 2015, p. 107). En la explicación que hemos desarrollado más arriba y que adicionalmente se verá reflejada en la propuesta de más abajo, parece más coherente con el sistema una versión matizada de la segunda tesis.

(i) A diferencia del sistema alemán del § 130 I OWiG (Ley de Contravenciones Administrativas), basado exclusivamente en una omisión propia de deberes de control (Aufsichtsmaßnahmen) — con una exigencia atenuada de vínculo de ilicitud—-, el sistema chileno tiene la particularidad de exigir una «consecuencialidad» fáctica-normativa entre la persona jurídica y la conducta de la persona física. Dicho concepto (consecuencia), que obliga a adoptar un criterio de responsabilidad «adscriptiva», es complejo porque parece exigir la distinción de hechos o circunstancias dominadas por una persona física, pero que son efectos (denominados consecuencias o resultados) de otros hechos o circunstancias que resultan ser sus causas (relación empírica) y que son de dominio de una persona jurídica. Al encontrarse en una misma línea de causalidad fáctica, la complejidad radica en atribuir al mismo tiempo dos dominios del hecho diferentes, ubicando a dos agentes autorresponsables en un mismo nivel de «capacidad de arbitrio» sobre el hecho. Aquello sucedería también si en su lugar se adoptara una relación lógico-normativa, pero de base causal general: i. adoptar un nivel de relación fáctica general y, luego, ii. adoptar un criterio «de relevancia fáctica y/o jurídica como corrección» (FIGUEROA, 2019, p. 48). Como solución, solo cabe adoptar un criterio mixto, que no sería incompatible ni con la lógica ni con el texto legal; esto es, un sistema de «responsabilidad-agente» que atribuya a ciertas propiedades del «agente» el proceso al que pertenece el hecho (no causal) y luego, el desarrollo de un criterio corrector «de relevancia» jurídica (similar a la imputación objetiva). La autoría siempre quedará radicada en la persona física.

(ii) La eliminación de la lógica empírica causal y la adopción de la responsabilidad de «agencia» (autor/posición) en el art. 3 de la ley chilena exige distinguir dos niveles de atribución e imputación asociados, pero basados tanto en la naturaleza diferenciada de ambos como en los distintos niveles de competencia normativa en la protección de los bienes jurídicos de cada agente. Aquello garantizaría una independencia de cada agente respecto del obrar del otro, tanto en un sentido de expresión fáctica como normativa, pero también su vínculo funcional: el hecho como expresión de la persona y el proceso como expresión del ente. Así, se generan dos procedimientos de imputación que se encuentran vinculados y son dependientes entre sí: de la conducta autorresponsable individual de la persona física (dominio de hecho) y la de la organización que se expresa en la atribución al ente de «procesos» (dominio del proceso) al que pertenece la conducta de la persona física (CIGÜELA, 2015, p. 278) y respecto del cual excepcionalmente tiene competencia normativa por la conducta de terceros. 
a. «Organización interna defectuosa» (entorno interno): en primer lugar, es necesario atribuir a la persona jurídica particular el ejercicio desordenado de la libertad empresarial en su capacidad auto organizativa, que genera «procesos riesgosos» (en infracción al deber de dirección). Específicamente, se hace necesario atribuir a la organización la existencia ya sea de estructuras con procesos de «dominación y control» o de «planeación u organización» con capacidad de incidir negativamente en el «entorno interno y externo» (colaboradores, trabajadores u órganos), a partir de valores, creencias, normas, rituales, políticas y otros «modelos de significados compartidos» (CAMARENA MARTÍNEZ, 2016, p. 146), que resultan ser riesgosos potencialmente para el entorno externo en que se produce el delito (a partir de numerus clausus de delitos).

b. «Dominio de la organización sobre el proceso» (entorno externo): en segundo lugar, una vez identificado el ente organizado defectuosamente — en tanto sujeto garante de control por incumbencia (deber de supervisión) — se debe atribuir el «dominio sistemático de la organización»(HEINE, 1998, pp. 90 y ss.) sobre el «proceso concreto» en que se desarrolló la conducta de la persona física y que se relaciona con el «entorno social externo». Como se analizó más arriba, lo que es propio y distintivo de las organizaciones es su capacidad de vincularse recíprocamente con el entorno «por medio de procesos»; por lo mismo, es necesario vincular la conducta de la persona física — espacio temporalmente — con una parte definida de las actividades y recursos de la organización — entre ellos, órganos, y colaboradores - que transforman elementos de entrada en elementos de salida (productos, servicios, etc.). Estos procesos pueden ser definidos como estratégicos, operativos o de soporte (GIBSON, 2002), de manera que se presentan en distintos niveles y grados de formalidad.

Por lo mismo, se trata de desarrollar dos tipos de atribución: i. identificar un ámbito de interacción en que se desarrolla la conducta de la persona física y atribuirle la calidad de proceso; e ii. identificar aquel proceso — con idoneidad de influencia social recíproca negativa con el entorno- y atribuirlo espaciotemporalmente a la organización, como propio.

Esta vinculación de dominio sobre el proceso (gestión) permitirá, a su vez, definir su competencia de control excepcional sobre riesgos de las conductas delictivas de terceros (autorresponsables) y, a su vez, en el ámbito de las conductas motivadas, posibilitadas y/o facilitadas por los incentivos desordenados propios de la organización (competitividad y maximización en la búsqueda de beneficios) (NIETO MARTÍN, 2017, p. 169).

A este nivel, será necesario identificar la vulneración a los deberes de supervigilancia y control sobre el proceso «concreto» (distinto a la mera organización riesgosa). 
c. «El proceso como ámbito motivacional de la persona física» (particular): en tercer lugar, se hace necesario definir la capacidad de motivación del «proceso concreto» a la persona física, lo que completa el «dominio sistemático de la organización» (HEINE, 1998, pp. 90 y ss.).

En el caso de la regulación chilena, aquello se produce, de manera muy exigente, de dos formas: i. asegurándose de que la persona física sea un órgano con una posición apical en la organización (lo que se interpreta como una posición de poder fáctico y funcional en un proceso) y ii. definiendo si la persona física ha actuado, directa e inmediatamente en interés o provecho organizativo (art. 3) o, en caso de una imputación autónoma - en que no es posible definir normativa e individualmente dicho vínculo motivacional de interés - que haya actuado «dentro del ámbito de funciones y atribuciones propias» (art. 5).

d. Organización como ámbito de control del cumplimiento del deber ajeno: «vínculo de antijuridicidad»: ya que solo excepcionalmente el ente es competente por las conductas de terceros [por el mero vínculo «de organización-proceso» (riesgoso)] se hace necesario determinar el merecimiento de pena, corrigiendo dicho vínculo meramente procedimental, de manera de relacionar el ejercicio ilícito de la libertad de autoorganización manifestado en procesos (en vulneración a deberes de dirección y control) con la conducta autodeterminada de la persona física: a aquello el legislador le llama «consecuencia» (normativa) del incumplimiento.

El asunto es de suma importancia, ya que si la pretensión del sistema de responsabilidad (del modelo) es que este «ilícito propio» de la persona jurídica constituya de alguna forma también una manifestación o expresión del injusto penal del delito base (en o de la persona jurídica), no solo debe acreditarse una vinculación abstracta y normativa, sino esencialmente «una vinculación de sentido» (SILVA SÁNCHEZ, 2016, p. 892). En parte, aquello se ha logrado por medio de la vinculación organizacional de la empresa con la persona física (vía procesos). Este proceso solo es «parecido» al análisis de la imputación de resultado, pero no equivalente en sentido. Por lo mismo, no es posible acceder a la idea expuesta por GómezJara de que con este análisis se culmina el análisis del defecto de organización, por un lado, en tanto lo que existía hasta ahora solo puede constituir un «indicio» de un defecto de organización y, por otro, debe adoptar la lógica de la imputación del resultado: «Así, puede que se compruebe que la persona jurídica se encuentra defectuosamente organizada respecto de un determinado grupo de riesgo penal, pero el que se realizó finalmente en el resultado es otro distinto» (GÓMEZ-JARA, 2006, p. 130). En un sentido similar, Silva Sánchez, haciendo un paralelo con la imputación objetiva del resultado, propone que dicha relación de sentido sea analizada en dos ámbitos, similar a la relación de peligro y la relación de riesgo en Roxin. Esto es, definir si i. el delito se ha visto o no favorecido por la organización defec- 
tuosa y ii. en aquellos que, si se ha visto favorecido, lo es en términos normativos, esto es, analizar el comportamiento alternativo conforme a derecho (SILVA SÁNCHEZ, 2016, p. 892).

En realidad, acá no se trata necesariamente de imputar la conducta o el hecho de la persona física como un «resultado» al dominio de la persona jurídica, sino de terminar de verificar que la infracción normativa por defecto organizacional es la razón jurídica y socialmente determinante del proceso de gestión del ente al que pertenece la conducta.

Nos parece, en todo caso, que no se trata de cualquier tipo de análisis normativo, sino de uno que analiza el diseño real de los «procesos de gestión existentes en las empresas» destinados a la dirección y al control de los riesgos o de los «procesos» de coordinación de medidas, comúnmente denominados compliance program o de sus similares. Precisamente, por tratarse de estas las expresiones fácticas y normativas de los entes, es que el análisis normativo, al igual que el fáctico, debe reconocer aquella realidad.

Así, una posibilidad de interpretación, acudiendo a la teoría de la evitabilidad (KÜHL, 2012, $\S 17, \mathrm{~nm} .51)$ es la de exigir un ejercicio analítico normativo denominado en la dogmática alemana «conexión de la infracción del deber» (Pflichtwidrigkeitszusammenhang) (GIMBERNAT, 2015, p. 26). El aplicador del derecho, para vincular la vulneración de los deberes y el delito de la persona física, deberá preguntarse: si de haberse aplicado el «cuidado debido» (en el cumplimiento de los deberes) en la organización del ente habría sido posible excluir o evitar con una probabilidad rayana en la certeza (KÜHL, 2012, § 17 nm. 52; DUTTGE, 2017, nm 181 y s.; FREUND, 2009, pp. 191 y ss.; FRISCH, 2015, pp. 98 y s.) o con una probabilidad preponderante (DUTTGE, 2017, § 15) el delito de la persona física (resultado). Probablemente, la limitación de esta propuesta radique en que está diseñado como criterio para atribuir al sujeto no solo el quebrantamiento de un deber de conducta, sino esencialmente el delito atribuible a tal quebrantamiento.

En el caso de atribución de conductas autónomas y autodeterminadas de una persona física, es muy difícil llegar a sostener con seguridad que se trata de un «resultado» que no se habría producido con el comportamiento correcto (ROXIN, 1962, p. 422). Una alternativa, por lo mismo, es la teoría del «incremento del riesgo», y que se concreta en si la conducta conforme al deber hubiese significado una mayor o menor probabilidad de que ello hubiera sido así (GIMBERNAT ORDEIG, 2015, p. 29). Así las cosas, si no es posible sostener un incremento del riesgo ni que se incremente el peligro de comisión de delitos, no puede serle atribuido al sujeto como una conducta ilícita vinculada al resultado.

En Chile, Hernández, como una forma de superar las dificultades de la teoría del incremento del riesgo y de causalidad hipotética para la responsabilidad de las personas jurídicas, propone un modelo de imputación extraído del parágrafo 130 I OWiG (Ley de Contravenciones Administrativas) alemán y que establece un criterio menos exigente, pero que sería una derivación del criterio propuesto por Roxin del incremento del riesgo. La interrogante consistiría aquí en si la existencia de un modelo de prevención adecuado ¿habría impedido o 
dificultado considerablemente la comisión del delito? Este criterio sería aún más plausible si, como lo hace el propio Hernández, se entendiera que los modelos de cumplimiento en tanto procesos, como el del art. 4, si bien no son exigidos, ofrecen un estándar de cumplimiento de deberes. De ahí, sostiene este autor, que si el legislador ofrece este estándar — que en todo caso no está diseñado en términos de evitación absoluta - le bastará como criterio de imputación, con que «hubiera podido impedirlo razonablemente». Esta tesis fue acogida, o al menos anunciada, por el Tribunal de Juicio Oral de Arica (RUC N ${ }^{\circ} 1100770074-3$ RIT $\mathrm{N}^{\circ} 33-2014 .^{7}$

La crítica que deberá sortear, sin embargo, es que de alguna forma tiende a eliminar el resultado (la exigencia de la comisión del delito de la persona física) como elemento relevante del injusto (FEIJÓO SÁNCHEZ, 2017, pp. 61 y ss.), en circunstancias que resulta ser un elemento del injusto típico. Este sería precisamente el problema de la propuesta de Hernández para la responsabilidad penal de las personas jurídicas, en tanto esta tesis desconocería de manera expresa una exigencia típica y que resulta ser la más relevante de la «atribución»a las personas jurídicas de una conducta de un tercero: «ser consecuencia de», lo que representa mucho más que un mero hipotético haber «impedido o dificultado considerablemente».

\section{CONCLUSIÓN}

I. El legislador chileno ha adoptado una posición en el diseño del sistema de responsabilidad penal de las personas jurídicas en que concibe solo a la persona física (humana) como susceptible de ser sujeto de imputación principal en la ejecución de delitos de la parte especial. Las personas jurídicas, sin embargo, son generadoras autónomas de «procesos» dominados enteramente por la racionalidad humana colectiva y, en cuanto tal, pueden ser titulares también de deberes y, en algún grado también, de merecimiento de pena.

2. El sistema de imputación adoptado por la ley chilena — de carácter mixto y dependiente de la conducta injusta de la persona física - reconoce las diferencias no solo de concepción antropológica de la persona física y de la persona jurídica, sino también de las fórmas de expresión fáctico-social de que son capaces ambas. Aquello explica que, si bien los delitos de la parte especial solo pueden ser ejecutados por las personas físicas, en alguna medida también pueden ser expresión —y, por lo mismo, atribuídos como talde los procesos organizados y desarrollados por las personas jurídicas. 
3. La propuesta final, relativa al concepto de «consecuencia», se construye sobre la base de 1) superar la concepción de las personas jurídicas como mera ficción con analogía a las personas naturales [responsabilidad de «agencia» (autor/posición)] y 2) eliminar la lógica causal que presupone que un agente obra de forma extrínseca sobre otro «agente» afectando su capacidad de autodeterminación. Basado en lo anterior, este trabajo ha concluido que el sistema de responsabilidad exige distinguir dos niveles de atribución e imputación asociados, pero basados tanto en la naturaleza diferenciada de ambos sujetos como en los distintos niveles de competencia normativa en la protección de los bienes jurídicos de cada agente: i. identificar un ámbito de interacción en que se desarrolla la conducta de la persona física y atribuirle la calidad de proceso; e ii. identificar aquel proceso - con idoneidad de influencia social recíproca negativa con el entorno- $\mathrm{y}$ atribuirlo espaciotemporalmente a la organización como propio.

4. Esta vinculación de dominio sobre el proceso (gestión) permite, a su vez, definir su competencia de control excepcional sobre riesgos de las conductas delictivas de terceros (autorresponsables) y, a su vez, en el ámbito de las conductas motivadas, posibilitadas y/o facilitadas por los incentivos desordenados propios de la organización, que permitirá definir la conducta de la persona física como «consecuencia normativa» del proceso de la persona jurídica.

\section{AGRADECIMIENTOS}

El autor agradece al ayudante de la cátedra de Derecho Penal en la Universidad de los Andes (Chile), Alberto Cruz, por su colaboración en la revisión y corrección formal de este trabajo, y al Prof. Dr. Francisco Bedecarratz por sus comentarios críticos al manuscrito. Este artículo ha sido en parte escrito y completado durante una estadía de investigación en la Universidad de Navarra, España, financiada por una beca de la Fundación Carolina (España) y la Universidad de los Andes (Chile), a quienes se extienden los agradecimientos. Especial agradecimiento a los colegas académicos de la Universidad de Navarra (España), Prof. Pablo Sánchez-Ostíz, Prof. Elena Iñigo y Prof. Mario Pereira, por la hospitalidad y apoyo científico permanente. 
¿IMPUTACIÓN PENAL POR EL ÁMBITO DE ORGANIZACIÓN DE TERCEROS?: EL CASO CHILENO DE LA RESPONSABILIDAD PENAL : 24

\section{BIBLIOGRAFÍA}

ARTAZA, Osvaldo. Empresa como sujeto de imputación de responsabilidad penal, fundamentos y límites. Madrid, Barcelona: Marcial Pons, 2013a.

ARTAZA, Osvaldo. Sistemas de prevención de delitos o programas de cumplimiento. Breve descripción de las reglas técnicas de gestión del riesgo empresarial y su utilidad en sede jurídico penal. Política Criminal, v. 8 , n. 16, diciembre 2013b, art. 6, p. 544-573.

BASCUR, Gonzalo. Consideraciones sobre la delimitación entre coautoría y complicidad en el contexto del Derecho Penal chileno. Revista de Estudios de la Justicia, Universidad de Chile, n. 2, 2015, p. 175-226.

BEDECARRATZ, Francisco. La indeterminación del criminal compliance y el principio de legalidad. Política Criminal, v. 13, n. 25, Art. 6, p. 208-232 (Julio 2018). Disponible en: http:/ / www.politicacriminal. cl/Vol_13/n_25/Vol13N25A6.pdf.

BEDECARRATZ, Francisco. Rechtsvergleichende Studien zor Strafbarkeit juristischer Personen. Alemania: Nomos Verlag, 2015.

CAMARENA MARTÍNEZ, José Luis. La organización como sistema: el modelo organizacional contemporáneo. Revista OIkos Polis, Revista Latinoamericana, v. 1, n. 1, jul./ dic., 2016.

CELAYA, Pedro. La responsabilidad civil del empresario por el hecho de su dependiente. (Un intento por sistematizar la jurisprudencia chilena). Revista de Derecho Universidad de Concepción, n. 197, año LXIII, 1995, p. $101-145$.

CIGÜELA, Javier. La culpabilidad colectiva en el derecho penal. Madrid, Barcelona: Marcial Pons, 2015.

CORDINI, Nicolás Santiago. La imputación según Kant. ¿Reconoce este autor diversos niveles de análisis? Revista de Derecho de la Pontificia Universidad Católica de Valparaíso, XLVII, Valparaíso, $2^{\text {do }}$ semestre de 2016, p. $427-459$.

DANNECKER, Gerhard. Zur Notwendigkeit der Einführung kriminalrechtlicher Sanktionen gegen Verbänden. Überlegungen zu den anforderungen und zur Ausgestaltung eines Verbandsstrafrechts. Goltdammer's Archiv für Strafrecht (GA). C. F. Müller, 2001, p. 101-130.

DE AQUINO, Tomás. Exposicion del De Trinitate de Boecio. Introduccion, traduccion y notas de A. García Marques y J. A. Fernandez. Pamplona: Eunsa, 1986. 
DUTTGE, Gunnar. StGB § 15 Vorsätzliches und fahrlässiges Handeln. En: JOECKS, W.; MIEBACH, K. (eds.). Münchener Kommentar zum Strafgesetzbuch. t. 1, 3. ed. München: C.H. Beck, 2017.

FEIJÓO SÁNCHEZ, Bernardo. La persona jurídica como sujeto de imputación jurídico-penal. En: BAJO FERNÁNDEZ, Miguel et al. (ed.). Tratado de responsabilidad de las personas jurídicas, segunda edición. España, Pamplona: Civitas; Thomson Reuters, 2016, p. 49-64.

FIGUEROA, Sebastián. Adscrición y reacción. Madrid: Marcial Pons, 2019.

FINNIS, John. Tomas de Aquino, teoría moral, política y jurídica. Chile: IES (Instituto de Estudios de la Sociedad), 2019.

FLETCHER, George. Gramática del Derecho Penal. Buenos Aires: Hammurabi, 2008.

FREUND, Georg. Strafrecht. Allgemeiner Teil. 2. ed. Berlin: Springer, 2009.

FRISCH, Wolfgang. La imputación objetiva del resultado. Desarrollo, fundamento y cuestiones abiertas. Barcelona: Atelier, 2015.

FRISCH, Wolfgang. Sobre la punibilidad de personas jurídicas. En: VAN WEEZEL, Alex (ed.). Humanizar y renovar el Derecho Penal, Estudios en memoria de Enrique Cury. Santiago: Thomson Reuters, 2013, p. 805-839.

GIBSON, James. Las Organizaciones - Comportamiento, Estructura, Procesos. 11. ed. Chile: Ed. Mc Graw Hill / Irwin, 2002.

GIERKE, Otto von. Die Genossenschaftstheorie und die deutsche Rechtsprechung Gebundene. Berlin: Nachdruck der Ausgabe, 1887, Hildesheim, 1963.

GIMBERNAT ORDEIG, Enrique. Teoría de la evitabilidad versus teoría del aumento del riesgo. ADPCP, v. LXVIII, 2015.

GÓMEZ-JARA, Carlos.¿Imputabilidad de las personas jurídicas?. En: BAJO FERNANDEZ, Miguel; JORGE B., Agustín; SUAREZ G., Carlos (eds.). Libro Homenaje a D. Gonzalo Rodríguez Mourullo, 2005, p. $163-182$.

GÓMEZ-JARA, Carlos. Responsabilidad penal de los directivos de empresa en virtud de su dominio de la organización. Algunas consideraciones críticas. Cuadernos de política criminal, n. 88, 2006, p. $119-154$. 
GÓMEZ-JARA, Carlos. ¿Responsabilidad penal de todas las personas jurídicas? Una antecrítica al símil de la ameba acunado por Alex van Weezel. Política Criminal, v. 5, n. 10, Diciembre 2010, p. 455-475.

GÓMEZ-JARA, Carlos. Tomarse la responsabilidad penal de las personas jurídicas en serio: La culpabilidad de las personas jurídicas. En: CALCINA HANCCO, Aldo (ed.). Responsabilidad penal de las empresas y compliance program. Santiago de Chile, 2018, p. 65-89.

GÓMEZ-JARA, Carlos. CapítuloV. Fundamentos de la responsabilidad de las personas jurídicas. En: BAJO FERNÁNDEZ, Miguel; FEIJOO S., Bernardo; GÓMEZ-JARA, Carlos (coord.). Tratado de responsabilidad de las personas jurídicas. España, Pamplona: Civitas; Thomson Reuters, 2015, p. 89-115.

HEINE, Günter. Modelos de responsabilidad jurídico penal originaria de la empresa. En: GÓMEZ-JARA, Carlos (ed.). Modelos de autorresponsabilidad penal empresarial. Aranzadi:Thomson Reuters, 2006.

HEINE, Günter. Pladoyer fur ein Verbandsstrafrecht als "zweite Spur”. En: ALWART, H. (Hrsg.). Verantwortung und Steuerung von Unternehmen in der Marktwirtschaft. Munchen, 1998, p. 90-112.

HERNÁNDEZ, Héctor. Desafíos de la ley de responsabilidad penal de las personas jurídicas. Revista de Estudios de la Justicia, v. 16, 2012, p. 75-98.

HERNÁNDEZ, Héctor. La introducción de la responsabilidad penal de las personas jurídicas en Chile. Política Criminal, v. 5, n. 9, art. 5, 2010, p. 207-236.

HIRSCH, Hans Joachim. La cuestión de la responsabilidad penal de las asociaciones de personas. Anuario de Derecho Penal y Ciencias Penales, 1993, p. 1099 y ss.

HRUSCHKA, Joachim. Imputación y derecho penal. Montevideo, Buenos Aires: Editorial B de F, 2009.

HRUSCHKA, Joachim. Ordentlich und außerordentlich Zurechnung bei Pusendorf'. Zeitschrift für die gesamte Strafrechtswissenschaft, 96, p. 661-702, 1984.

JAKOBS, Günther. Strafbarkeit juristischer Personen? En: PRITTWITZ et al. (eds.). Festschrift fur Klaus Luderssen, 2002.

KANT, Immanuel. La metafísica de las costumbres (1979). Trad. Cortina y Conill, 1989.

KELSEN, Hans. Teoría Pura del Derecho. Trad. de la edicion francesa Moises Nilve. Buenos Aires: EUDEBA, 1960. 
KÜHL, Kristian. Strafrecht. Allgemeiner Teil. Munchen: Vahlen Studienreihe Jura, 2012.

KUHLEN, Lothar. Compliance y Derecho Penal en Alemania. En: MIR PUIG, Santiago et al. (dirs.). Responsabilidad de la empresa y compliance. Programas de prevención, detección y reacción penal. Madrid: Edisofer S. L., 2014, p. 89-125.

LAMPE, Hans Joachim. Systemunrecht und Unrechtssysteme. ZStW 106, 1994, p. 700 y ss.

LAUFER, William. Corporate liability, risk shifting and the paradox of compliance. Vanderbilt Law Review, v. 52, n. 5, 1999, p. 1343-1420.

MORGAN, Gareth. Imagenes de la organizacion. México: Alfaomega, 1996.

NEIRA, Ana María. La efectividad de los criminal compliance programs como objeto de prueba en el proceso penal. Política Criminal, v. 11, n. 22, diciembre 2016, art. 5, p. 467-520.

NIETO MARTÍN, Adán. La responsabilidad penal de las personas jurídicas: esquema de un modelo de responsabilidad penal. Madrid: Iustel, 2008.

NIETO MARTÍN, Adán. La autorregulación preventiva de la empresa como objeto de la política criminal. En: SILVA SÁNCHEZ, J. M. et al. Estudios de Derecho Penal, Homenaje al Profesor Mir Puig. Montevideo, Buenos Aires: Editorial B de F, 2017, p. 167-177.

ORTUZAR, Andrés. Modelo de atribución de responsabilidad penal en la Ley N. 20.393 que establece la responsabilidad penal de las personas jurídicas: ¿Culpabilidad de la empresa, heterorresponsabilidad o delito de infracción de deber? REJ - Revista de Estudios de la Justicia, n. 16, año 2012.

PARSONS, Talcott. Societies: Evolutionary and Comparative Perspectives. Englewood Cliffs, N.J.: PrenticeHall, 1966.

PENDAS, Benigno. Teoría del derecho y del Estado en Otto Von Gierke. Anuario de la Facultad de Derecho, n. 1, 1991-1992, p. 109-160.

PIÑA ROCHEFORT, Juan Ignacio. Modelos de prevención de delitos en la empresa. Chile: Abeledo Perrot, 2012.

ROBLES PLANAS, Ricardo. Estudios de dogmática jurídico-penal. Montevideo: Editorial B de F, 2015.

ROBINSON, Paul H.; DUBBER, Markus D. The American Model Code: A Brief Overview. New Criminal Law Review, 2007, p. 319-341. 
RODRÍGUEZ MOURULLO, Gonzalo. Derecho penal. Parte General. España:Vívitas, 1978.

ROSSO, Gian Franco. Los límites de la responsabilidad objetiva. México: Universidad Nacional Autónoma de México, Inst. de Investigaciones Jurídicas, 2016.

ROXIN, Claus. Strafrecht. AT, tomo I, C.H. Beck Verlag.

ROXIN, Claus. Pflichtwidrigkeit und Erfolg bei fahrlässigen Delikten. ZStW 74, 1962, p. 411-444.

SÁEZ CRUZ, Jesús. La causalidad personal: una propuesta zubiriana en diálogo con Mario Bunge. Parte II. The Xavier Zubiri Review, v. 11, 2009, p. 55-90.

SÁNCHEZ-OSTIZ, Pablo. Las normas de las personas jurídicas: ¡cómo es que responde penalmente quien no puede delinquir! VVAA, Estudios de Derecho Penal: homenaje al profesor Miguel Bajo, Silvina Bacigalupo, Bernardo Feijoo, Juan I. Echano, 2016, p. 609-628.

SAVIGNY, Friedrich Carl von. System des heutigen Römischen Rechts. Berlin: Band. 2, 1840, p. 235 y ss.

SCHROTH, Hans-Jürgen. Unternehmen als Normadressaten und Sanktionssubjekte. Eine Studie zum Unternehmensstrafrecht. Gießen: Brühlscher Verlag, 1993.

SILVA SÁNCHEZ, Jesús. "La evolución ideológica de la discusión sobre la 'responsabilidad penal' de las personas jurídicas”. Revista de Derecho Penal y Criminología, Memorias. XXX Jornadas Internacionales de Derecho Penal. Treinta años de evolución del derecho penal. Colombia: Universidad de Externado de Colombia, 2008, p. $129-148$.

SILVA SÁNCHEZ, Jesús. “Deberes de vigilancia y compliance empresarial”. En: SILVA SÁNCHEZ, J. M. Fundamentos del derecho penal de la empresa. Montevideo: B de F, 2014a, p. 193-245.

SILVA SÁNCHEZ, Jesús. "La responsabilidad penal de las personas jurídicas en el derecho español”. En: SILVA SANCHEZ, J. M. Fundamentos del derecho penal de la empresa. Montevideo: B de F, 2014b, p. $285-305$.

SILVA SÁNCHEZ, Jesús. La eximente de 'modelos de Prevencion de delitos', Fundamento y bases para una dogmática. En: VVAA. El Derecho Penal como teoría y como práctica. Libro en homenaje a Alfredo Etcheberry Orthusteguy. Thomson Reuters, 2016, p. 869-900.

TIEDEMANN, Klaus. Die 'Bebußung' von Unternehmen nach dem 2. Gesetz zur Bekämpfung der Wirtschaftskriminalität. En: Neue Juristische Wochenschrift (NJW), 1988, p. 1169-1174. 
UNDANGARIN, Jaime. La responsabilidad penal de la persona jurídica como modelo basado en el deber de cuidado y la previsibilidad a priori del nivel de probabilidad del riesgo. Tesis de Grado de Magister, Universidad Alberto Hurtado, 2014.

VAN WEEZEL, Alex. Contra la responsabilidad penal de las personas jurídicas. Política Crminal, v. 5, n. 9, 2010, p. 114-142.

VILLEGAS G., María de los Ángeles. La responsabilidad criminal de las personas jurídicas. La experiencia de Estados Unidos. Pamplona: Thomson Reuters, Aranzadi, 2016.

VON DER HEYDT, Ruben. Perspektivität von Freiheit und Determinismus. Berlín: Duncker \& Humblot, 2017.

ZULGADÍA ESPINAR, José Miguel. Societas delinquere potest (Analisis de la reforma operada en el Codigo Penal espanol por la LO 5/2010, de 22 de junio). La Ley Penal, n. 76, noviembre 2010, Editorial La Ley.

\section{Cómo CITAR ESTE ARTícULO:}

PALOMINOS, Gonzalo García. ¿Imputación penal por el ámbito de organización de terceros?: el caso chileno de la responsabilidad penal de las personas jurídicas. Revista Direito GV, v. 16, n. 3, set./dez. 2020, e1970. doi: http://dx.doi.org/10.1590/23176172201970 .
Gonzalo García Palominos

Doctor en Derecho por la Albert-Ludwigs-Universität Freiburg, Alemania, y académico del Departamento de Derecho Penal de la Universidad de los Andes (Chile).

ggarcialauandes.cl 